The original publication is available at www.springerlink.com

https://pubmed.ncbi.nlm.nih.gov/29500701/

Intensive Care Med 2018; 44: 449-463

\title{
FLUID THERAPY IN NEUROINTENSIVE CARE PATIENTS: ESICM CONSENSUS AND CLINICAL PRACTICE RECOMMENDATIONS
}

Mauro Oddo ${ }^{1}$, Daniele Poole ${ }^{2}$, Raimund Helbok ${ }^{3}$, Geert Meyfroidt ${ }^{4}$, Nino Stocchetti ${ }^{5}$, Pierre Bouzat ${ }^{6}$, Maurizio Cecconi ${ }^{7}$, Thomas Geeraerts ${ }^{8}$, Ignacio Martin-Loeches ${ }^{9}$, Hervé Quintard ${ }^{10}$, Fabio Silvio Taccone $^{11}$, Romergyiko G. Geocadin ${ }^{12}$, Claude Hemphill ${ }^{13}$, Carole Ichai ${ }^{14}$, David Menon ${ }^{15}$, Jean-François Payen $^{6}$, Anders Perner ${ }^{16}$, Martin Smith ${ }^{17}$, José Suarez ${ }^{12}$, Walter Videtta ${ }^{18}$, Elisa Zanier ${ }^{19}$, Giuseppe Citerio $^{20}$.

1. Department of Medical-Surgical Intensive Care Medicine, Centre Hospitalier Universitaire Vaudois (CHUV), University of Lausanne (UNIL), Faculty of Biology and Medicine (FBM), CH-1011 Lausanne, Switzerland.

2. Anesthesia and Intensive Care Operative Unit, S. Martino Hospital, Belluno, Italy. daniele.poole@alice.it.

3. Neurological Intensive Care Unit, Department of Neurology, Medical University of Innsbruck, Innsbruck, Austria

4. Department of Intensive Care Medicine, University Hospitals Leuven, Leuven, Belgium.

5. Fondazione IRCCS Ca' Granda-Ospedale Maggiore Policlinico, Department of Anesthesia and Critical Care, Neuroscience Intensive Care Unit, Milan, Italy. Department of Pathophysiology and Transplants, University of Milan, Milan, Italy.

6. Department of Anesthesia and Critical Care, CHU Grenoble Alpes, 38000, Grenoble, France.

7. Department of Anaesthesia and Intensive Care, St. George's University Hospital, London, UK.

8. Department of Anaesthesia and Intensive Care, Toulouse University Hospital, University Toulouse 3-Paul Sabatier, 31059 Toulouse, France.

9. Department of Intensive Care Medicine, St James's University Hospital, James's St, Ushers, P.O. Box 580, Dublin 8, Ireland.

10. Université Côte d'Azur, Service de réanimation médico-chirurgicale, Hôpital Pasteur 2, CHU de Nice, 06000 Nice, France; Unité CNRS 7275 Sophia-Antipolis, France

11. Department of Intensive Care, Erasme Hospital, Université Libre de Bruxelles, Brussels, Belgium

12. Neurosciences Critical Care, Departments of Anesthesiology and Critical Care Medicine, Neurology, and Neurosurgery, Johns Hopkins University, Baltimore, MD, United States 
13. Department of Neurology, University of California San Francisco, San Francisco, CA

14. Service de réanimation polyvalente, Hôpital Pasteur 2, CHU de Nice, 30 Voie Romaine, CS 51069, 06001, Nice Cedex 1, France

15. Division of Anaesthesia, University of Cambridge, Box 93, Addenbrooke's Hospital, Hills Road, Cambridge, Cambs, United Kingdom of Great Britain and Northern Ireland , CB2 $2 Q Q$

16. Department of Intensive Care 4131, Copenhagen University Hospital - Rigshospitalet, Copenhagen, Denmark.

17. Department of Neuroanesthesia and Neurocritical Care, The National Hospital for Neurosurgery and Neurology, University College London Hospitals, London, UK

18. Hospital Nacional Professor Alejandro Posadas, Buenos Aires, Argentina.

19. Department of Neuroscience, IRCCS - Istituto di Ricerche Farmacologiche Mario Negri, Milan, Italy.

20. School of Medicine and Surgery, University of Milan-Bicocca, Milan, Italy; Neurointensive Care, San Gerardo Hospital, ASST-Monza, 20900 Monza, Italy

\section{Funding and conflicts of interests}

The authors declare no conflict of interest for this manuscript.

No external funding has been obtained for this research. 


\section{ABSTRACT}

Objective. To report the ESICM Consensus and clinical practice recommendations on fluid therapy in neurointensive care patients.

Design. A consensus committee was conducted in October 2016 during ESICM LIVES2016, where a meeting was held with 22 international experts. Teleconferences and electronic-based discussions between the members of the committee subsequently served as an integral part of the development of the consensus process.

Methods. Population, intervention, comparison, and outcomes (PICO) questions were reviewed and updated as needed, and evidence profiles were generated. The consensus focused on three main topics: 1) general fluid resuscitation and maintenance, 2) hyperosmolar fluids for ICP control, 3) fluids for the management of delayed cerebral ischemia). After literature search for best available evidence, the principles of the Grading of Recommendations Assessment, Development, and Evaluation (GRADE) system were applied to assess the quality of evidence (from high to very low) and to formulate recommendations as strong or weak, or best practice statement when applicable. A modified Delphi process based on the integration of evidence provided by the literature and expert opinions - using a sequential approach for avoiding biases and misinterpretations - was used to generate final statements.

Results. The panel provided 28 statements, including 11 strong recommendations and 15 weak recommendations. No recommendations were provided for 2 questions.

Conclusions. We present the clinical practice recommendations on fluid therapy for neurointensive care patients.

Keywords: Evidence-based medicine - Guidelines - Fluids - Traumatic brain injury - Subarachnoid hemorrhage - Intracerebral hemorrhage - Stroke - Mannitol - Hypertonic - Neurointensive care. 


\section{INTRODUCTION}

Fluid therapy is a fundamental component of neurointensive care (NIC), with general indications (volume resuscitation and maintenance) and "neuro-specific" purposes (intracranial pressure [ICP] control, management of delayed cerebral ischemia [DCI]). Despite routine utilization, key questions such as preferred composition, optimal volume, choice and dose of hyperosmolar fluids to control ICP - remain unanswered. There is limited high-quality evidence or specific recommendations to guide fluid therapy in NIC patients, and physiologic triggers and monitoring endpoints of fluid therapy are not precisely defined.

The primary intention of these recommendations is to provide guidance to clinicians caring for NIC patients. In view of the low levels of evidence, they do not represent a standard of care, but rather the current best clinical practice.

\section{METHODOLOGY}

Below is a summary of important methodological considerations for the development of these consensus guidelines.

\section{Definitions}

We defined NIC patients as adult critically ill patients with acute brain injury (ABI) including severe traumatic brain injury (TBI), high-grade aneurysmal subarachnoid hemorrhage (SAH), or severe ischemic (AIS) or hemorrhagic (ICH) stroke.

\section{Registration}

The methodological plan for this systematic review was registered on PROSPERO, International prospective register of systematic reviews, with the ID 42016052123 (https://www.crd.york.ac.uk/prospero/display_record.php?RecordID=52123)

\section{Sponsorship}

No funding was provided. ESICM provided logistic support for the first meeting.

\section{Conflict-of-interest policy}

No industry input into guidelines development occurred. No consensus member received honoraria and the process relied solely on personal disclosures.

\section{Selection of committee members}

Participants were members of the European Society of Intensive Care Medicine (ESICM), Neurocritical Care Society (NCS) and Latin America Brain Injury Consortium (LABIC). Chairs and co-chairs were appointed by the NIC section of ESICM, with an external member (DP) providing methodological 
expertise for the Grading of Recommendations Assessment, Development and Evaluation (GRADE) process.

\section{Question development}

The focus of our academic exercise was on the management of NCC patients during the intensive care phase but did include aspects of the pre-hospital management whenever it was deemed important. The guideline panel was divided into three sections, according to the three main questions addressed:
1) General fluid management in $A B I$ patients,
2) Hyperosmolar fluids for ICP control and
3) Fluid therapy for the management of $\mathrm{DCl}$.

Topic selection was the responsibility of the group co-chairs (GM, NS, RH) and chairs (MO, GC), with input from the guideline panel in each group. All guideline questions were structured in the PICO format (population, intervention, control, and outcomes).

\section{Search strategy, data analysis, and grading of the evidence}

All the details of the search strategies and grading of the evidence, including advanced statistical approach as in meta-analyses and meta-regression, are detailed in the electronic supplementary material (ESM).

\section{Consensus methodology}

We used a modified Delphi process based on the integration of evidence provided in the literature review and expert opinions. All the results of the GRADING of the evidence were available to the panel through a web-based file. The chairs (MO, GC) integrated the initial questions with literature revision and grading, and formulated 4 mutually exclusive questions and 35 questions (clustered in five different sections) requiring a score ranging from 1 (strongly disagree) to 10 (strongly agree). These questions were submitted to the members of the panel through a web-based system. For each question or cluster of questions the experts could provide comments to clarify their answers. The answers were analysed by a non-voting member of the panel (DP). Answers providing scores were analysed as medians, $20^{\text {th }}$, and $80^{\text {th }}$ percentiles. Further, scores were clustered into low (1-3), intermediate (4-7), and high (8-10), and analysed with correspondence analysis. Both approaches were used to identify answers that provided clear-cut positions among experts, particularly those polarized on agreement or disagreement. Correspondence analysis was used to assess if single members of the panel provided specific response patterns, especially when intermediate positions were taken. The results of the analyses were returned to the panel anonymously. The same list of question was then submitted to the panel in a second round. 
On the basis of the analysis of the second round of questions, statements were formulated by the chairs (MO, GC) selecting questions with higher degrees of agreement, and then re-submitted to the panel. Answers were analysed with correspondence analysis to spot heterogeneity among the panel members. Single panel members who presented heterogeneous answer patterns were provided feedbacks on their answers with request to confirm their vote, to remove the risk of misinterpretations of some statements.

A final vote was required for confirmation, with $>80 \%$ of voting members necessary for a strong recommendation (in favour or against). When votes in favour or against (a mix of strong and weak options) didn't reach the $80 \%$ threshold, then a weak recommendation was provided. In case of minor concerns panel members could declare reservation. In case of major concerns a stand aside position was adopted, no blocking option was permitted, and reasons for concerns were reported.

\section{RESULTS}

\section{FLUIDS FOR THE GENERAL MANAGEMENT OF ABI PATIENTS}

\subsection{Analysis of available evidence}

Question 1: Is there evidence on efficacy and safety of albumin compared to crystalloids?

One multicenter RCT in AIS patients found comparable 90-day outcome of $25 \%$ albumin ( $n=422$ ) vs. normal saline (NS) ( $n=419)$, administered within 5 hours from emic strokeisch [19]. One single-center observational study $(n=82)$ in AIS patients found that high-dose albumin was associated with better outcome (OR 1.81 [95\% Cl 1.11-2.94]) [21]. These two studies were considered sufficiently homogeneous to contribute to the same body of evidence. GRADE: high quality evidence (in favour). The following studies, instead, were too heterogeneous to be combined in an overall body of evidence. Their individual grading (reported in the ESM), hence corresponds to the body of evidence grading.

A subgroup analysis performed on TBI patients from the multicenter SAFE trial found higher 2-year mortality ( 33.2 vs. $20.4 \%$ ) of $4 \%$ albumin ( $n=214$; note that the osmolality of the albumin solution in SAFE-TBI was 260 mosm/l) vs. NS ( $n=206$ ) [20]: the excess mortality was strikingly higher in severe TBI (41.8 vs. 22.2\%; RR 1.88 [95\% Cl 1.31-2.70]) vs. no significant difference in moderate TBI patients. GRADE: low quality evidence (against).

Two additional studies were analyzed. One multicenter propensity score adjusted study $(n=5400)$ [22] and one retrospective single-center study $(n=42)$ [23] in SAH patients found that albumin use was associated with better outcomes. GRADE: very low quality evidence (in favour).

Question 2: Is there evidence on efficacy and safety of synthetic colloids compared to crystalloids? 
Studies were too heterogeneous to be combined in an overall body of evidence. Their individual grading hence corresponds to the body of evidence grading.

One single-center propensity score matching study $(n=123)$ in SAH patients found that colloids (plasma, dextran, starch and/or albumin amongst 41 patients) were associated with significantly worse NIH Stroke Scale (NIHSS) [24]. GRADE: low quality evidence (against).

Two additional studies were analyzed. One study, examining data from SAH patients recruited from two RCTs $(n=160)$ found that the cumulative daily colloid dose (4\% gelatin or $6 \%$ penta-starch) was associated with worse 6-month Glasgow Outcome Score (GOS: adjusted OR 2.53 [95\% Cl 1.13-5.68]), while crystalloids (L/day) promoted favorable recovery (adjusted OR 0.27 [95\% Cl 0.11-0.67]) [25] GRADE: very low quality evidence (against).

In severe TBI patients, Cox proportional hazard modeling of single-center data $(n=171)$ found no association between cumulative penta-starch dose and mortality [26]. GRADE: very low quality evidence (against).

Question 3: Is there evidence on efficacy and safety of buffered crystalloid solutions compared to standard crystalloids?

No studies considered robust outcomes as survival and good neurological recovery.

Two small single-center RCTs, one in SAH patients $(n=36)$ [27] and another one in TBI patients $(n=41)$ [28] found that, compared to NS, buffered solutions reduced the rate of hyperchloremia (a secondary outcome in our revision design). The body of evidence is considered low (high degree of imprecision due to the small sample size and the risk of inflated effect [29]); therefore a protective, although quantitatively small, effect of buffered solutions could not be defined. The studies had a sufficiently homogenous design to allow a meta-analysis (Figure in ESM). GRADE: low quality evidence (in favour).

In addition, one RCT in TBI patients ( $\mathrm{n}=34$, two centers) found that Ringer's lactate (RL) significantly reduced serum sodium and osmolarity compared to hypertonic saline (HTS), however average serum sodium and osmolarity (148 $\mathrm{mEq} / \mathrm{L}$ and $320 \mathrm{mOsm} / \mathrm{L}$, respectively) were never into the high range with the use of either fluids [30]. GRADE: very low-quality evidence (in favour).

Question 4: Is there evidence on efficacy and safety of infusions of hypertonic fluids compared to isotonic fluids, given as resuscitation solutions?

Studies were too heterogeneous to be combined in an overall body of evidence. Their individual grading hence corresponds to the body of evidence grading. Importantly, all studies were performed in TBI patients.

One RCT comparing a bolus infusion $(250 \mathrm{~mL}$ ) of $7.5 \%$ HTS to RL ( $n=113$ patients in each group) given in the pre-hospital setting reported no differences in 6-month mortality and GOS [31]. GRADE: high quality evidence (against). 
Baker et al. in a RCT $(n=64)$ compared 7.5\% HTS/6\% dextran solutions to NS (given as a single $250 \mathrm{~mL}$ resuscitation dose) and found no significant difference in 30-day mortality and GOS [32]. GRADE: low quality evidence (against).

Shackford et al. in a RCT ( $n=34$, two centers) comparing $1.6 \%$ HTS to RL for resuscitation purposes reported no significant difference in GOS at hospital discharge [30]. GRADE: very low quality evidence (against).

\subsection{FLUIDS FOR THE GENERAL MANAGEMENT OF ABI PATIENTS: RECOMMENDATIONS.}

A total of 20 recommendations (8 strong and 12 weak recommendations) are summarized in Table 1.

\section{HYPEROSMOLAR FLUIDS FOR THE MANAGEMENT OF ELEVATED ICP}

\subsection{Analysis of the available evidence}

Question 1: Are available hyperosmolar fluids effective in reducing ICP?

$R C T^{\prime} S$

We found one comparative RCT (60 patients, 2 centers) in severe TBI patients showing that hypertonic lactate, administered as a continuous prophylactic infusion over the first 48 hours from ICU admission, was more effective than NS in preventing episodes of elevated ICP (>20 mmHg) (\% ICP reduction $30 \%$ [95\% $\mathrm{Cl}-50.4$ to $-4.8 \%$ ]; NNTB 3 [95\% Cl 2-21]) [33].

\section{Observational studies}

Despite limitations (small sample size, no adjustments for confounders), a high number of beforeafter studies investigating the effectiveness of mannitol (MAN) and HTS in reducing ICP across a spectrum of different $A B I$ conditions were available [34-60], allowing a specific meta-analysis to examine whether a common trend could be determined. The dedicated PubMed search code, the studies selection criteria, and the methodology used for meta-analysis and meta-regression are extensively reported in the ESM.

The flow chart of selection for inclusion of MAN and HTS studies in meta-analyses and metaregressions is summarized in Figure in ESM.

Mannitol

Meta-analysis revealed that MAN was associated with a $10.9 \mathrm{mmHg}$ reduction in ICP $(95 \%-\mathrm{Cl}$ 8.3-14.5 $\mathrm{mmHg}, p<0.001$, Figure 1). Heterogeneity was statistically significant $\left(\mathrm{I}^{2}=69 \%\right.$; $95 \%-\mathrm{Cl} 45-90 \%, p<$ 0.001). The sensitivity analysis using high correlation between before and after measurements was consistent with these findings (ESM fig). 
By meta-regression, for every $1 \mathrm{mmHg}$ increase in baseline ICP, MAN bolus yielded an extra 0.55 mmHg ICP reduction ( $p<0.001$, Figure 2$)$; the heterogeneity estimate dropped to $0 \%(p=0.255)$. However, the degree of imprecision was high and this finding should be interpreted with prudence. The meta-regression assuming high correlation provided similar results, but heterogeneity was highly significant ( $p<0.001)$, (fig ESM).

Using funnel plots, asymmetry was found to be statistically significant in the meta-analysis ( $p=0.005$, Figure in ESM) and improved strikingly with the meta-regression ( $p=0.897$, Figure in ESM), a result confirmed by the sensitivity analysis.

Mannitol dose

By meta-regression, the extent of ICP reduction did not correlate with MAN dose $(0.42 \mathrm{mmHg}$ per 100 $\mathrm{mg} / \mathrm{Kg}, p=0.478$ ). However, by multivariable meta-regression analysis after adjusting for initial ICP, the relationship of MAN dose with ICP became statistically significant in the main analysis $(0.78$ $\mathrm{mmHg}$ for every $100 \mathrm{mg} / \mathrm{Kg}$ increase, $p=0.003$ ), a result confirmed by the less conservative sensitivity analysis. Obviously, heterogeneity $p$ values had an opposite behaviour, with absence of statistical significance in the main analysis and highly significant heterogeneity in the sensitivity analysis. The results of this analysis should be treated with the greatest of caution because an insufficient number of studies were included in the model.

\section{Hypertonic saline.}

HTS was associated with an average $8.8 \mathrm{mmHg}$ ICP reduction $(95 \%-\mathrm{Cl} 6.5-11.1 \mathrm{mmHg}, p<0.001$, Figure 3). Heterogeneity was high $\left(I^{2}=77 \%, 95 \%-C l 45-94, p<0.001\right)$. The meta-regression using baseline ICP with post-HTS ICP reduction produced a statistically significant result (slope $0.343, p=$ 0.040), despite heterogeneity ( $\mathrm{Cl} 0-91 \%$, Figure 4 ) and two studies with Cook distances of 3.4 and 1.8 that strongly influenced the slope.

In summary, there is evidence to indicate that the use of both MAN and HTS are associated with a reduction ICP; importantly no RCTs were identified. GRADE: low quality evidence (in favour).

Question 2: Is there any evidence that hyperosmolar fluids have different efficacy (more or less effective) in reducing ICP?

Studies were too heterogeneous to be combined in an overall body of evidence. Their individual grading hence corresponds to the body of evidence grading. Heterogeneity in study design, mainly treatment protocols, did not allow us to perform a meta-analysis. Results were also heterogeneous and are reported in detail in the ESM.

Nine RCTs were found, comparing different hyperosmolar fluids administered as infusion boluses to treat elevated ICP: six studies were performed in TBI patients [35, 38, 61-64], two studies with an heterogeneous population of TBI and SAH patients [65, 66] and one study with AIS patients [57]. Eight studies compared MAN to HTS [35, 38, 57, 62], and one study compared MAN to HTL [61]. Evidence 
from all these RCTs (besides one [57]) was equally rated. GRADE: low quality evidence (in favour or against according to specific study findings).

One observational study comparing hypertonic drugs was found [67].

RCTs comparing hypertonic fluids given in equiosmolar doses ( 7 studies, $N=186$ patients)

One study ( $n=9$ in a crossover design, single-centre) found that $7.5 \%$ HTS/6\% dextran vs. $20 \%$ MAN yielded a greater ICP reduction at $60 \mathrm{~min}(-5 \mathrm{mmHg}$ [95\%-Cl -10.8 to -3$], p$ 0.014) [65], while four other studies ( $n=20$ [38], $n=47$ [35], $n=38$ [62], $n=29$ [63]) found that 7.5\%,3\%, 15\% HTS and $20 \%$ MAN were equally effective in reducing ICP. One study $(n=9)$ investigating ICP reduction using $7.5 \%$ HTS/6\% dextran and $20 \% \mathrm{MAN}$, did not compare the two groups with formal statistical tests and received a very low evidence grading [57].

Ichai et al. ( $n=34$, single-centre) found that half-molar hypertonic lactate was more effective than $20 \%$ MAN in reducing elevated ICP, however the difference in ICP decrease at 4 hours in favour of hypertonic lactate $(2.7 \mathrm{mmHg})$, although statistically significant, was of limited clinical relevance [61].

RCTs comparing hypertonic fluids given in non equiosmolar doses ( 2 studies, $n=52$ patients)

In these studies, HTS osmotic charge was higher than that of MAN, therefore favouring HTS. Vialet et al. ( $n=20$, single-centre) found that $7.5 \%$ HTS was more effective than half the osmotic dose of $20 \%$ MAN in reducing the daily number of episodes with elevated ICP $<25 \mathrm{mmHg}$ (6 vs. 13) [64]. A second study ( $n=32$ ) found a statistically significant ICP percentage reduction with HTS/HES 200/0.5 compared to $15 \%$ MAN[66].

Observational studies comparing hypertonic fluids

We found an additional multicentre observational study that reported superiority of $3 \%$ HTS over $20 \%$ MAN in reducing ICP. The evidence provided by this study was rated as very low quality (in favour) [67].

Question 3: Is there evidence supporting the use of hyperosmolar fluids without ICP monitoring? One RCT performed on $\mathrm{ICH}$ patients $(\mathrm{n}=24)$ found that MAN and HTS had comparable effects on reduction in midline shift assessed by MRI [68]. A second RCT in severe AIS patients $(n=9)$ found that MAN and HTS had comparable effects on CBF increase measured by PET [69]. GRADE: very lowquality evidence.

Several observational studies investigated the effects of hyperosmolar fluids (MAN or HTS) in patients in whom monitoring consisted of trans-cranial Doppler $[41,59,70]$, positron emission tomography $[36,55]$, Xenon-CT $[59,71,72]$, CT scan (to measure brain volume and shift, water content) [44, 7376] or EEG [77]. GRADE: very low-quality evidence.

Question 4: Is there evidence that hyperosmolar fluids administration improve outcome? 


\section{Randomized controlled trials}

The RCTs were heterogeneous and could not be combined in a meta-analysis. Their individual grading hence corresponds to the body of evidence grading.

One multicentre RCT performed in TBI patients_( $n=226)$ found that pre-hospital resuscitation with HTS vs. NS did not change 6-month GOS-E [31].GRADE: high quality evidence.

One RCT performed on TBI patients ( $n=60$; two centers) found that prophylactic half-molar hypertonic lactate, although significantly reducing the number of episodes of ICPO increase over $20 \mathrm{mmHg}$, did not improve 6-month outcome compared to NS [33]. In a previous study in TBI patients, hypertonic lactate, given to treat elevated ICP, was associated with better 12-month outcome compared to MAN (69 vs. $35 \%$ ), non-significant result ( $p$ 0.084) [61]

In another RCT in TBI patients, there was no mortality difference between 20\% MAN and 7.5\% HTS used to treat elevated ICP $>15 \mathrm{mmHg}$ [35].

The three RCTs were equally downgraded for methodological limitations. GRADE: low quality evidence (in favour or against according to the study findings).

\section{Observational studies}

One study using a propensity-score matched design applied to data from ICH patients included in the INTERACT-2 trial found no significant outcome difference between MAN-treated $(n=1533)$ and nonMAN treated ( $n=993$ ) group [78]. GRADE: low quality evidence.

One study reported that MAN may negatively affect AIS patients outcomes [79], while in another study HTS/dextran improved survival of TBI patients with hypotension [80]. GRADE: very low quality evidence.

\subsection{HYPEROSMOLAR FLUIDS FOR THE MANAGEMENT OF ELEVATED ICP: RECOMMENDATIONS.}

A total of 9 recommendations (2 strong recommendations and 7 weak recommendations) are summarized in Table 1.

\section{FLUIDS FOR THE MANAGEMENT OF CEREBRAL ISCHEMIA}

\subsection{Analysis of the available evidence}

Question 1: Is there evidence to prefer specific fluids (crystalloids or colloids) in the prevention of DCI (CBF or clinical) in SAH patients?

Studies were too heterogeneous to be combined in an overall body of evidence. Their individual grading hence corresponds to the body of evidence grading. We considered studies focused on the prevention of new secondary cerebral ischemic events, i.e. vasospasm and $\mathrm{DCl}$ and its consequences, in SAH patients. We report separately RCTs and observational studies. 


\section{Randomized controlled trials.}

Compared to normovolemia (2L/day crystalloids), triple $\mathrm{H}$ therapy_(4 L/day hypervolemic hypertensive haemodilution fluid therapy, including colloids and crystalloids) did not change the proportion of patients with vasospasm signs on TCD, regional CBF, and 1-year GOS ( $n=32$ patients, 2 centres) [81]. Lennihan et al. ( $n=82$ patients, single-centre) similarly found no improvement of regional and global $\mathrm{CBF}$, or differences in the rate of vasospasm and cerebral infarction between prophylactic hypervolemic therapy (including colloids and crystalloids) and normovolemic therapy [82]. GRADE: very low-quality evidence (against). A third RCT was not included in our analysis because it combined multiple interventions (including volume expansion) for the prevention of vasospasm, thus not providing reliable information of single elements of the therapeutic approach [83].

\section{Observational studies.}

We included 13 observational studies, all single-centre, including small sample sizes and having heterogeneous treatment protocols and outcomes. It was therefore not possible to combine them in a single body of evidence. We made a detailed reporting of our grading process only for six studies using statistical techniques to adjust for confounding factors: several studies found that higher fluid volumes and positive fluid balance were associated with worse morbidity and neurological outcomes $[22,84,85]$.

When examining studies specifically addressing $\mathrm{DCl}$, Ibrahim et al., using a propensity-score matched analysis on 123 patients found that the administration of colloids and a positive fluid balance were associated with significantly worse outcomes [24].

Another study ( $n=288$ patients), also specifically addressing $D C l$ and adjusted for confounders with propensity scores, found that positive fluid balance was associated with worse functional outcome [86]. Among studies not performing statistical adjustment for confounders, six examined the effect of fluid therapy on CBF and CBF surrogates. Hypervolemia (using colloids and crystalloids) modestly increased regional $\mathrm{CBF}$ but without improving $\mathrm{PbtO}_{2}$ [87]. Volume expansion with $\mathrm{HTS}$ was associated with an improvement of $\mathrm{PbtO}_{2}$ and $\mathrm{CBF}[71,88,89]$. In contrast, volume expansion with albumin was associated with a CBF decrease [90], while NS had no effect on CBF [91].

All the studies were equally downgraded. GRADE: very low quality evidence (in favour or against according to the study findings).

\section{Question 2: Does fluid therapy in the management of $D C l$ influence outcome?}

Studies were too heterogeneous to be combined in an overall body of evidence. Their individual grading hence corresponds to the body of evidence grading. 
A multicenter RCT AIS patients $(n=1267)$ found that haemodilution (by venesection followed by dextran replacement) vs. standard treatment did not change 6-month outcome [92]. GRADE: moderate quality evidence (against).

In AIS patients ( $\mathrm{N}=193$ ) daily fluid intake $>1650 \mathrm{ml}$ was associated with malignant brain oedema (OR 13.86 [95 \% Cl 5.11-37.60]) [93]. GRADE: very low quality evidence (against).

Additional observational studies (not performing any statistical adjustment for confounders, using small sample size and heterogeneous design to be assessed with a meta-analytical approach) are listed below for, at best, hypotheses-generating purposes:

- CBF: In patients with SAH and vasospasm, boluses of NS ( $n=6)$ [94] or HTS $(n=35)$ [59] significantly improved CBF, whilst hypervolemia (albumin, dextran, and 10\% glycerol) normalized CBF in the cerebral hemisphere where perfusion was reduced by vasospasm [95]. In contrast, volume expansion with colloids and albumin [96] and isovolemic hemodilution obtained by venisection and infusion of albumin and dextran [97] did not increase CBF.

- Clinical endpoints: Two studies found that hypervolemia (albumin, glycerol, dextran, or plasma) targeted to hemodynamic monitoring (Swan-Ganz catheter) led to neurologic improvement and absence of progression to infarction in most patients $[98,99]$. Several limitations (small sample size, absence of an instrumental diagnosis of vasospasm, no specific definition of teatment, and lack of adjustment for confounding factors) preclude any definitive conclusion.

Question 3: Is there enough evidence to prefer specific fluids (crystalloids/colloids) in the management of cerebral ischemia for CBF augmentation/clinical outcome?

One observational study ( $\mathrm{n}=160$ patients) found that higher colloid dose (L/day) was associated with unfavourable 6-month GOS (OR 2.53 [95\% Cl 1.13-5.68]), while at the contrary crystalloids were associated with a reduced likelihood of unfavourable outcome (OR 0.27 [95\% Cl 0.11-0.67]) [25]. GRADE: very low quality evidence (against).

Question 4: Is brain monitoring useful as a trigger or endpoint to guide fluid therapy in the management of $D C l$ ?

One study on $S A H$ patients $(\mathrm{n}=10)$ found that albumin ( $250 \mathrm{~mL}$ fluid bolus) increased cardiac index and improved $\mathrm{PbtO}_{2}$ [100], however the limited sample size, despite using multivariable approach to account for multiple measurements, raises internal and external validity issues. GRADE: very low quality evidence (in favour).

Question 5: Should a change in neurological status trigger a modification in fluid management away from normovolemia in patients with cerebral ischemia?

Studies were too heterogeneous to be combined in an overall body of evidence. Their individual grading hence corresponds to the body of evidence grading. 
Two studies treated new neurological symptoms in SAH patients with hypervolemia (albumin, glycerol, dextran, or plasma). A subset of patients were monitored with Swan-Ganz catheter: neurologic improvement and absence of progression to infarction in most cases led the authors to conclude that hypervolemic therapy was effective $[98,99]$. The two studies, however, had very serious limitations due to the small sample size, to the absence of a instrumental diagnosis of vasospasm, no specific definition of teatment, and lack of adjustment for confounding factor. GRADE for both studies: very low quality evidence (in favour).

Question 6: Is there a place for early-goal directed fluid therapy in the management of DCI? One RCT in SAH patients ( $\mathrm{n}=160$ ), comparing fluid management targeted to keep high global enddiastolic volume index (GEDI, measured by trans-pulmonary thermodilution) vs. standard management found no effect on $\mathrm{DCl}$ and 3 moths poor outcome frequency [101]. A predefined analysis on high-grade SAH patients that were stratified at randomization, showed a statistically significant reduction of both outcomes. However, according to our calculation that used the same statistical tests as the authors neither result was statistically significant ( $p=0.10$ for $\mathrm{DCl}$ and $p=0.07$ for 3-month poor outcome). GRADE: moderate quality evidence (against).

Three observational studies, using logistic regression models, found that trans-pulmonary thermodilution (with the use of Cardiac Function Index [102] and GEDI [103, 104]) was associated with better outcomes. GRADE: very low quality evidence (in favour).

\subsection{FLUIDS FOR THE MANAGEMENT OF CEREBRAL ISCHEMIA: RECOMMENDATIONS.}

Two recommendations (1 strong recommendation and 1 weak recommendation) are summarized in Table 1.

A summary of all RCT's on fluid therapy in NIC patients is given in Table 2. 


\section{References}

1. Higgins JP, Thompson SG: Quantifying heterogeneity in a meta-analysis. Stat Med 2002, 21(11):1539-1558.

2. Higgins JP, Thompson SG, Deeks JJ, Altman DG: Measuring inconsistency in meta-analyses. BMJ 2003, 327(7414):557-560.

3. Egger M, Davey Smith G, Schneider M, Minder C: Bias in meta-analysis detected by a simple, graphical test. BMJ 1997, 315(7109):629-634.

4. Ioannidis JP, Trikalinos TA: The appropriateness of asymmetry tests for publication bias in meta-analyses: a large survey. CMAJ 2007, 176(8):1091-1096.

5. Balshem $H$, Helfand $M$, Schunemann HJ, Oxman AD, Kunz R, Brozek J, Vist GE, Falck-Ytter $Y$, Meerpohl J, Norris S et al: GRADE guidelines: 3. Rating the quality of evidence. J Clin Epidemiol 2011, 64(4):401-406.

6. Guyatt GH, Oxman AD, Sultan S, Glasziou P, Akl EA, Alonso-Coello P, Atkins D, Kunz R, Brozek J, Montori $V$ et al: GRADE guidelines: 9. Rating up the quality of evidence. J Clin Epidemiol 2011, 64(12):1311-1316.

7. Guyatt GH, Oxman AD, Vist G, Kunz R, Brozek J, Alonso-Coello P, Montori V, Akl EA, Djulbegovic B, Falck-Ytter $Y$ et al: GRADE guidelines: 4. Rating the quality of evidence--study limitations (risk of bias). J Clin Epidemiol 2011, 64(4):407-415.

8. Katz MH: Multivariable analysis: a primer for readers of medical research. Ann Intern Med 2003, 138(8):644-650.

9. Moher D, Schulz KF, Altman DG, Consort G: The CONSORT statement: revised recommendations for improving the quality of reports of parallel-group randomized trials. Ann Intern Med 2001, 134(8):657-662.

10. Bagley SC, White $\mathrm{H}$, Golomb BA: Logistic regression in the medical literature: standards for use and reporting, with particular attention to one medical domain. J Clin Epidemiol 2001, 54(10):979-985.

11. Babyak MA: What you see may not be what you get: a brief, nontechnical introduction to overfitting in regression-type models. Psychosom Med 2004, 66(3):411-421.

12. Peduzzi P, Concato J, Feinstein AR, Holford TR: Importance of events per independent variable in proportional hazards regression analysis. II. Accuracy and precision of regression estimates. J Clin Epidemiol 1995, 48(12):1503-1510.

13. Sun GW, Shook TL, Kay GL: Inappropriate use of bivariable analysis to screen risk factors for use in multivariable analysis. J Clin Epidemiol 1996, 49(8):907-916.

14. Austin PC, Tu JV: Automated variable selection methods for logistic regression produced unstable models for predicting acute myocardial infarction mortality. J Clin Epidemiol 2004, 57(11):1138-1146.

15. Sylvestre MP, Huszti E, Hanley JA: Do OSCAR winners live longer than less successful peers? A reanalysis of the evidence. Ann Intern Med 2006, 145(5):361-363; discussion 392.

16. Braitman LE, Rosenbaum PR: Rare outcomes, common treatments: analytic strategies using propensity scores. Ann Intern Med 2002, 137(8):693-695.

17. Juni $P$, Altman DG, Egger M: Systematic reviews in health care: Assessing the quality of controlled clinical trials. BMJ 2001, 323(7303):42-46.

18. Liberati A, Altman DG, Tetzlaff J, Mulrow C, Gotzsche PC, loannidis JP, Clarke M, Devereaux PJ, Kleijnen J, Moher D: The PRISMA statement for reporting systematic reviews and metaanalyses of studies that evaluate health care interventions: explanation and elaboration. PLoS Med 2009, 6(7):e1000100.

19. Ginsberg MD, Palesch YY, Hill MD, Martin RH, Moy CS, Barsan WG, Waldman BD, Tamariz D, Ryckborst KJ, Alias et al: High-dose albumin treatment for acute ischaemic stroke (ALIAS) Part 2: a randomised, double-blind, phase 3, placebo-controlled trial. Lancet Neurol 2013, 12(11):1049-1058.

20. Investigators SS, Australian, New Zealand Intensive Care Society Clinical Trials G, Australian Red Cross Blood S, George Institute for International H, Myburgh J, Cooper DJ, Finfer S, Bellomo R, Norton R et al: Saline or albumin for fluid resuscitation in patients with traumatic brain injury. N Engl J Med 2007, 357(9):874-884. 
21. Palesch YY, Hill MD, Ryckborst KJ, Tamariz D, Ginsberg MD: The ALIAS Pilot Trial: a doseescalation and safety study of albumin therapy for acute ischemic stroke--II: neurologic outcome and efficacy analysis. Stroke 2006, 37(8):2107-2114.

22. Kuwabara K, Fushimi K, Matsuda S, Ishikawa KB, Horiguchi H, Fujimori K: Association of early post-procedure hemodynamic management with the outcomes of subarachnoid hemorrhage patients. J Neurol 2013, 260(3):820-831.

23. Suarez JI, Shannon L, Zaidat OO, Suri MF, Singh G, Lynch G, Selman WR: Effect of human albumin administration on clinical outcome and hospital cost in patients with subarachnoid hemorrhage. J Neurosurg 2004, 100(4):585-590.

24. Ibrahim GM, Macdonald RL: The effects of fluid balance and colloid administration on outcomes in patients with aneurysmal subarachnoid hemorrhage: a propensity scorematched analysis. Neurocrit Care 2013, 19(2):140-149.

25. Tseng MY, Hutchinson PJ, Kirkpatrick PJ: Effects of fluid therapy following aneurysmal subarachnoid haemorrhage: a prospective clinical study. Br J Neurosurg 2008, 22(2):257-268.

26. Sekhon MS, Dhingra VK, Sekhon IS, Henderson WR, McLean N, Griesdale DE: The safety of synthetic colloid in critically ill patients with severe traumatic brain injuries. J Crit Care 2011, 26(4):357-362.

27. Lehmann L, Bendel S, Uehlinger DE, Takala J, Schafer M, Reinert M, Jakob SM: Randomized, double-blind trial of the effect of fluid composition on electrolyte, acid-base, and fluid homeostasis in patients early after subarachnoid hemorrhage. Neurocrit Care 2013, 18(1):512.

28. Roquilly A, Loutrel O, Cinotti R, Rosenczweig E, Flet L, Mahe PJ, Dumont R, Marie Chupin A, Peneau C, Lejus $C$ et al: Balanced versus chloride-rich solutions for fluid resuscitation in brain-injured patients: a randomised double-blind pilot study. Crit Care 2013, 17(2):R77.

29. Ioannidis JP: Why most discovered true associations are inflated. Epidemiology 2008, 19(5):640-648.

30. Shackford SR, Bourguignon PR, Wald SL, Rogers FB, Osler TM, Clark DE: Hypertonic saline resuscitation of patients with head injury: a prospective, randomized clinical trial. $J$ Trauma 1998, 44(1):50-58.

31. Cooper DJ, Myles PS, McDermott FT, Murray LJ, Laidlaw J, Cooper G, Tremayne AB, Bernard SS, Ponsford J, Investigators HTSS: Prehospital hypertonic saline resuscitation of patients with hypotension and severe traumatic brain injury: a randomized controlled trial. JAMA 2004, 291(11):1350-1357.

32. Baker AJ, Rhind SG, Morrison LJ, Black S, Crnko NT, Shek PN, Rizoli SB: Resuscitation with hypertonic saline-dextran reduces serum biomarker levels and correlates with outcome in severe traumatic brain injury patients. J Neurotrauma 2009, 26(8):1227-1240.

33. Ichai C, Payen JF, Orban JC, Quintard H, Roth H, Legrand R, Francony G, Leverve XM: Halfmolar sodium lactate infusion to prevent intracranial hypertensive episodes in severe traumatic brain injured patients: a randomized controlled trial. Intensive Care Med 2013, 39(8):1413-1422.

34. Bentsen G, Breivik H, Lundar T, Stubhaug A: Hypertonic saline (7.2\%) in 6\% hydroxyethyl starch reduces intracranial pressure and improves hemodynamics in a placebo-controlled study involving stable patients with subarachnoid hemorrhage. Crit Care Med 2006, 34(12):2912-2917.

35. Cottenceau V, Masson F, Mahamid E, Petit L, Shik V, Sztark F, Zaaroor M, Soustiel JF: Comparison of effects of equiosmolar doses of mannitol and hypertonic saline on cerebral blood flow and metabolism in traumatic brain injury. J Neurotrauma 2011, 28(10):20032012.

36. Diringer MN, Scalfani MT, Zazulia AR, Videen TO, Dhar R, Powers WJ: Effect of mannitol on cerebral blood volume in patients with head injury. Neurosurgery 2012, 70(5):1215-1218; discussion 1219.

37. Eskandari R, Filtz MR, Davis GE, Hoesch RE: Effective treatment of refractory intracranial hypertension after traumatic brain injury with repeated boluses of $14.6 \%$ hypertonic saline. $J$ Neurosurg 2013, 119(2):338-346.

38. Francony G, Fauvage B, Falcon D, Canet C, Dilou H, Lavagne $\mathrm{P}$, Jacquot C, Payen JF: Equimolar doses of mannitol and hypertonic saline in the treatment of increased intracranial pressure. Crit Care Med 2008, 36(3):795-800. 
39. Hartl R, Ghajar J, Hochleuthner H, Mauritz W: Hypertonic/hyperoncotic saline reliably reduces ICP in severely head-injured patients with intracranial hypertension. Acta Neurochir Suppl 1997, 70:126-129.

40. Helbok R, Kurtz P, Schmidt JM, Stuart RM, Fernandez L, Malhotra R, Presciutti M, Ostapkovich ND, Connolly ES, Lee $\mathrm{K}$ et al: Effect of mannitol on brain metabolism and tissue oxygenation in severe haemorrhagic stroke. J Neurol Neurosurg Psychiatry 2011, 82(4):378383.

41. Huang SJ, Chang L, Han YY, Lee YC, Tu YK: Efficacy and safety of hypertonic saline solutions in the treatment of severe head injury. Surg Neurol 2006, 65(6):539-546; discussion 546.

42. Kerwin AJ, Schinco MA, Tepas JJ, 3rd, Renfro WH, Vitarbo EA, Muehlberger M: The use of $23.4 \%$ hypertonic saline for the management of elevated intracranial pressure in patients with severe traumatic brain injury: a pilot study. J Trauma 2009, 67(2):277-282.

43. Launey $Y$, Nesseler N, Le Maguet P, Malledant Y, Seguin P: Effect of osmotherapy on optic nerve sheath diameter in patients with increased intracranial pressure. J Neurotrauma 2014, 31(10):984-988.

44. Lescot T, Degos V, Zouaoui A, Preteux F, Coriat P, Puybasset L: Opposed effects of hypertonic saline on contusions and noncontused brain tissue in patients with severe traumatic brain injury. Crit Care Med 2006, 34(12):3029-3033.

45. Major EH, O'Connor P, Mullan B: Single bolus $30 \%$ hypertonic saline for refractory intracranial hypertension. Ir J Med Sci 2015, 184(1):159-165.

46. Marshall LF, RW SM, Rauscher LA, Shapiro HM: Mannitol dose requirements in brain-injured patients. J Neurosurg 1978, 48(2):169-172.

47. Mendelow AD, Teasdale GM, Russell T, Flood J, Patterson J, Murray GD: Effect of mannitol on cerebral blood flow and cerebral perfusion pressure in human head injury. J Neurosurg 1985, 63(1):43-48.

48. Miller JD, Piper IR, Dearden NM: Management of intracranial hypertension in head injury: matching treatment with cause. Acta Neurochir Suppl (Wien) 1993, 57:152-159.

49. Muizelaar JP, Lutz HA, 3rd, Becker DP: Effect of mannitol on ICP and CBF and correlation with pressure autoregulation in severely head-injured patients. J Neurosurg 1984, 61(4):700-706.

50. Oddo M, Levine JM, Frangos S, Carrera E, Maloney-Wilensky E, Pascual JL, Kofke WA, Mayer SA, LeRoux PD: Effect of mannitol and hypertonic saline on cerebral oxygenation in patients with severe traumatic brain injury and refractory intracranial hypertension. J Neurol Neurosurg Psychiatry 2009, 80(8):916-920.

51. Rockswold GL, Solid CA, Paredes-Andrade E, Rockswold SB, Jancik JT, Quickel RR: Hypertonic saline and its effect on intracranial pressure, cerebral perfusion pressure, and brain tissue oxygen. Neurosurgery 2009, 65(6):1035-1041; discussion 1041-1032.

52. Roquilly A, Mahe PJ, Latte DD, Loutrel O, Champin P, Di Falco C, Courbe A, Buffenoir K, Hamel $O$, Lejus $C$ et al: Continuous controlled-infusion of hypertonic saline solution in traumatic brain-injured patients: a 9-year retrospective study. Crit Care 2011, 15(5):R260.

53. Rosner MJ, Coley I: Cerebral perfusion pressure: a hemodynamic mechanism of mannitol and the postmannitol hemogram. Neurosurgery 1987, 21(2):147-156.

54. Sakowitz OW, Stover JF, Sarrafzadeh AS, Unterberg AW, Kiening KL: Effects of mannitol bolus administration on intracranial pressure, cerebral extracellular metabolites, and tissue oxygenation in severely head-injured patients. J Trauma 2007, 62(2):292-298.

55. Scalfani MT, Dhar R, Zazulia AR, Videen TO, Diringer MN: Effect of osmotic agents on regional cerebral blood flow in traumatic brain injury. J Crit Care 2012, 27(5):526 e527-512.

56. Schwarz S, Georgiadis D, Aschoff A, Schwab S: Effects of hypertonic (10\%) saline in patients with raised intracranial pressure after stroke. Stroke 2002, 33(1):136-140.

57. Schwarz S, Schwab S, Bertram M, Aschoff A, Hacke W: Effects of hypertonic saline hydroxyethyl starch solution and mannitol in patients with increased intracranial pressure after stroke. Stroke 1998, 29(8):1550-1555.

58. Soustiel JF, Mahamid E, Chistyakov A, Shik V, Benenson R, Zaaroor M: Comparison of moderate hyperventilation and mannitol for control of intracranial pressure control in patients with severe traumatic brain injury--a study of cerebral blood flow and metabolism. Acta Neurochir (Wien) 2006, 148(8):845-851; discussion 851.

59. Tseng MY, Al-Rawi PG, Czosnyka M, Hutchinson PJ, Richards H, Pickard JD, Kirkpatrick PJ: Enhancement of cerebral blood flow using systemic hypertonic saline therapy improves 
outcome in patients with poor-grade spontaneous subarachnoid hemorrhage. J Neurosurg 2007, 107(2):274-282.

60. Ware ML, Nemani VM, Meeker M, Lee C, Morabito DJ, Manley GT: Effects of 23.4\% sodium chloride solution in reducing intracranial pressure in patients with traumatic brain injury: a preliminary study. Neurosurgery 2005, 57(4):727-736; discussion 727-736.

61. Ichai C, Armando G, Orban JC, Berthier F, Rami L, Samat-Long C, Grimaud D, Leverve X: Sodium lactate versus mannitol in the treatment of intracranial hypertensive episodes in severe traumatic brain-injured patients. Intensive Care Med 2009, 35(3):471-479.

62. Jagannatha AT, Sriganesh K, Devi BI, Rao GS: An equiosmolar study on early intracranial physiology and long term outcome in severe traumatic brain injury comparing mannitol and hypertonic saline. J Clin Neurosci 2016, 27:68-73.

63. Sakellaridis N, Pavlou E, Karatzas S, Chroni D, Vlachos K, Chatzopoulos K, Dimopoulou E, Kelesis C, Karaouli V: Comparison of mannitol and hypertonic saline in the treatment of severe brain injuries. J Neurosurg 2011, 114(2):545-548.

64. Vialet R, Albanese J, Thomachot L, Antonini F, Bourgouin A, Alliez B, Martin C: Isovolume hypertonic solutes (sodium chloride or mannitol) in the treatment of refractory posttraumatic intracranial hypertension: $2 \mathrm{~mL} / \mathrm{kg} 7.5 \%$ saline is more effective than $2 \mathrm{~mL} / \mathrm{kg}$ 20\% mannitol. Crit Care Med 2003, 31(6):1683-1687.

65. Battison C, Andrews PJ, Graham C, Petty T: Randomized, controlled trial on the effect of a $20 \%$ mannitol solution and a $7.5 \%$ saline/6\% dextran solution on increased intracranial pressure after brain injury. Crit Care Med 2005, 33(1):196-202; discussion 257-198.

66. Harutjunyan L, Holz C, Rieger A, Menzel M, Grond S, Soukup J: Efficiency of 7.2\% hypertonic saline hydroxyethyl starch $200 / 0.5$ versus mannitol $15 \%$ in the treatment of increased intracranial pressure in neurosurgical patients - a randomized clinical trial [ISRCTN62699180]. Crit Care 2005, 9(5):R530-540.

67. Mangat HS, Chiu YL, Gerber LM, Alimi M, Ghajar J, Hartl R: Hypertonic saline reduces cumulative and daily intracranial pressure burdens after severe traumatic brain injury. J Neurosurg 2015, 122(1):202-210.

68. Misra UK, Kalita J, Vajpayee A, Phadke RV, Hadique A, Savlani V: Effect of single mannitol bolus in intracerebral hemorrhage. Eur J Neurol 2007, 14(10):1118-1123.

69. Diringer MN, Scalfani MT, Zazulia AR, Videen TO, Dhar R: Cerebral hemodynamic and metabolic effects of equi-osmolar doses mannitol and $23.4 \%$ saline in patients with edema following large ischemic stroke. Neurocrit Care 2011, 14(1):11-17.

70. Ye H, Su Y: Hemodynamic effects of mannitol infusion in patients with acute intracerebral hemorrhage. Acta Cir Bras 2013, 28(2):106-111.

71. Al-Rawi PG, Tseng MY, Richards HK, Nortje J, Timofeev I, Matta BF, Hutchinson PJ, Kirkpatrick PJ: Hypertonic saline in patients with poor-grade subarachnoid hemorrhage improves cerebral blood flow, brain tissue oxygen, and pH. Stroke 2010, 41(1):122-128.

72. Jafar JJ, Johns LM, Mullan SF: The effect of mannitol on cerebral blood flow. J Neurosurg 1986, 64(5):754-759.

73. Manno EM, Adams RE, Derdeyn CP, Powers WJ, Diringer MN: The effects of mannitol on cerebral edema after large hemispheric cerebral infarct. Neurology 1999, 52(3):583-587.

74. Nath F, Galbraith S: The effect of mannitol on cerebral white matter water content. J Neurosurg 1986, 65(1):41-43.

75. Qureshi Al, Suarez JI, Bhardwaj A, Mirski M, Schnitzer MS, Hanley DF, Ulatowski JA: Use of hypertonic (3\%) saline/acetate infusion in the treatment of cerebral edema: Effect on intracranial pressure and lateral displacement of the brain. Crit Care Med 1998, 26(3):440446.

76. Videen TO, Zazulia AR, Manno EM, Derdeyn CP, Adams RE, Diringer MN, Powers WJ: Mannitol bolus preferentially shrinks non-infarcted brain in patients with ischemic stroke. Neurology 2001, 57(11):2120-2122.

77. Huang Z, Dong W, Yan Y, Xiao Q, Man Y: Effects of intravenous mannitol on EEG recordings in stroke patients. Clin Neurophysiol 2002, 113(3):446-453.

78. Wang X, Arima H, Yang J, Zhang S, Wu G, Woodward M, Munoz-Venturelli P, Lavados PM, Stapf C, Robinson T et al: Mannitol and Outcome in Intracerebral Hemorrhage: Propensity Score and Multivariable Intensive Blood Pressure Reduction in Acute Cerebral Hemorrhage Trial 2 Results. Stroke 2015, 46(10):2762-2767. 
79. Bereczki D, Mihalka L, Szatmari S, Fekete K, Di Cesar D, Fulesdi B, Csiba L, Fekete I: Mannitol use in acute stroke: case fatality at 30 days and 1 year. Stroke 2003, 34(7):1730-1735.

80. Wade CE, Grady JJ, Kramer GC, Younes RN, Gehlsen K, Holcroft JW: Individual patient cohort analysis of the efficacy of hypertonic saline/dextran in patients with traumatic brain injury and hypotension. J Trauma 1997, 42(5 Suppl):S61-65.

81. Egge A, Waterloo K, Sjoholm H, Solberg T, Ingebrigtsen T, Romner B: Prophylactic hyperdynamic postoperative fluid therapy after aneurysmal subarachnoid hemorrhage: a clinical, prospective, randomized, controlled study. Neurosurgery 2001, 49(3):593-605; discussion 605-596.

82. Lennihan L, Mayer SA, Fink ME, Beckford A, Paik MC, Zhang H, Wu YC, Klebanoff LM, Raps EC, Solomon RA: Effect of hypervolemic therapy on cerebral blood flow after subarachnoid hemorrhage : a randomized controlled trial. Stroke 2000, 31(2):383-391.

83. Rosenwasser RH, Delgado TE, Buchheit WA, Freed MH: Control of hypertension and prophylaxis against vasospasm in cases of subarachnoid hemorrhage: a preliminary report. Neurosurgery 1983, 12(6):658-661.

84. Martini RP, Deem S, Brown M, Souter MJ, Yanez ND, Daniel S, Treggiari MM: The association between fluid balance and outcomes after subarachnoid hemorrhage. Neurocrit Care 2012, 17(2):191-198.

85. Tagami T, Kuwamoto K, Watanabe A, Unemoto K, Yokobori S, Matsumoto G, Igarashi Y, Yokota H, Group SAHPS: Effect of triple-h prophylaxis on global end-diastolic volume and clinical outcomes in patients with aneurysmal subarachnoid hemorrhage. Neurocrit Care 2014, 21(3):462-469.

86. Kissoon NR, Mandrekar JN, Fugate JE, Lanzino G, Wijdicks EF, Rabinstein AA: Positive Fluid Balance Is Associated With Poor Outcomes in Subarachnoid Hemorrhage. J Stroke Cerebrovasc Dis 2015, 24(10):2245-2251.

87. Muench E, Horn P, Bauhuf C, Roth H, Philipps M, Hermann P, Quintel M, Schmiedek P, Vajkoczy P: Effects of hypervolemia and hypertension on regional cerebral blood flow, intracranial pressure, and brain tissue oxygenation after subarachnoid hemorrhage. Crit Care Med 2007, 35(8):1844-1851; quiz 1852.

88. Al-Rawi PG, Zygun D, Tseng MY, Hutchinson PJ, Matta BF, Kirkpatrick PJ: Cerebral blood flow augmentation in patients with severe subarachnoid haemorrhage. Acta Neurochir Suppl 2005, 95:123-127.

89. Tseng MY, Al-Rawi PG, Pickard JD, Rasulo FA, Kirkpatrick PJ: Effect of hypertonic saline on cerebral blood flow in poor-grade patients with subarachnoid hemorrhage. Stroke 2003, 34(6):1389-1396.

90. Yamakami I, Isobe K, Yamaura A: Effects of intravascular volume expansion on cerebral blood flow in patients with ruptured cerebral aneurysms. Neurosurgery 1987, 21(3):303-309.

91. Dhar R, Scalfani MT, Zazulia AR, Videen TO, Derdeyn CP, Diringer MN: Comparison of induced hypertension, fluid bolus, and blood transfusion to augment cerebral oxygen delivery after subarachnoid hemorrhage. J Neurosurg 2012, 116(3):648-656.

92. Haemodilution in acute stroke: results of the Italian haemodilution trial. Italian Acute Stroke Study Group. Lancet 1988, 1(8581):318-321.

93. Dharmasaroja PA: Fluid Intake Related to Brain Edema in Acute Middle Cerebral Artery Infarction. Trans/ Stroke Res 2016, 7(1):49-53.

94. Jost SC, Diringer MN, Zazulia AR, Videen TO, Aiyagari V, Grubb RL, Powers WJ: Effect of normal saline bolus on cerebral blood flow in regions with low baseline flow in patients with vasospasm following subarachnoid hemorrhage. J Neurosurg 2005, 103(1):25-30.

95. Mori K, Arai H, Nakajima K, Tajima A, Maeda M: Hemorheological and hemodynamic analysis of hypervolemic hemodilution therapy for cerebral vasospasm after aneurysmal subarachnoid hemorrhage. Stroke 1995, 26(9):1620-1626.

96. Kim CY, Paek SH, Seo BG, Kim JH, Han DH: Changes in vascular responses of the basilar artery to acetylcholine and endothelin-1 in an experimental rabbit vasospasm model. Acta Neurochir (Wien) 2003, 145(7):571-577.

97. Ekelund A, Reinstrup P, Ryding E, Andersson AM, Molund T, Kristiansson KA, Romner B, Brandt L, Saveland H: Effects of iso- and hypervolemic hemodilution on regional cerebral blood flow and oxygen delivery for patients with vasospasm after aneurysmal subarachnoid hemorrhage. Acta Neurochir (Wien) 2002, 144(7):703-712; discussion 712-703. 
98. Shimoda M, Oda S, Tsugane R, Sato O: Intracranial complications of hypervolemic therapy in patients with a delayed ischemic deficit attributed to vasospasm. J Neurosurg 1993, 78(3):423-429.

99. Tanabe T, Saitoh T, Tachibana S, Takagi H, Yada K: Effect of hyperdynamic therapy on cerebral ischaemia caused by vasospasm associated with subarachnoid haemorrhage. Acta Neurochir (Wien) 1982, 63(1-4):291-296.

100. Kurtz P, Helbok R, Ko SB, Claassen J, Schmidt JM, Fernandez L, Stuart RM, Connolly ES, Badjatia N, Mayer SA et al: Fluid responsiveness and brain tissue oxygen augmentation after subarachnoid hemorrhage. Neurocrit Care 2014, 20(2):247-254.

101. Mutoh T, Kazumata K, Terasaka S, Taki Y, Suzuki A, Ishikawa T: Early intensive versus minimally invasive approach to postoperative hemodynamic management after subarachnoid hemorrhage. Stroke 2014, 45(5):1280-1284.

102. Mutoh T, Kazumata K, Terasaka S, Taki Y, Suzuki A, Ishikawa T: Impact of transpulmonary thermodilution-based cardiac contractility and extravascular lung water measurements on clinical outcome of patients with Takotsubo cardiomyopathy after subarachnoid hemorrhage: a retrospective observational study. Crit Care 2014, 18(4):482.

103. Tagami T, Kuwamoto K, Watanabe A, Unemoto K, Yokobori S, Matsumoto G, Yokota H, Group SAHPS: Optimal range of global end-diastolic volume for fluid management after aneurysmal subarachnoid hemorrhage: a multicenter prospective cohort study. Crit Care Med 2014, 42(6):1348-1356.

104. Yoneda H, Nakamura T, Shirao S, Tanaka N, Ishihara H, Suehiro E, Koizumi H, Isotani E, Suzuki M, Group SAHPS: Multicenter prospective cohort study on volume management after subarachnoid hemorrhage: hemodynamic changes according to severity of subarachnoid hemorrhage and cerebral vasospasm. Stroke 2013, 44(8):2155-2161. 
Table 1: Summary of recommendations (see methods for details). Using a modified Delphi process, we integrate the evidence provided by the literature review and expert opinions. Some recommendations are based only on expert opinion and should be considered as best practice. Strong recommendation (for or against) $>80 \%$ of voting members. When votes for or against (a mix of strong and weak options) didn't reach the $80 \%$ threshold, then a weak recommendation was provided. In case of minor concerns panel members could declare reservation. In case of major concerns a stand aside position was adopted.

\begin{tabular}{|c|c|c|}
\hline & & RECOMMENDATIONS \\
\hline $\begin{array}{l}\text { FLUIDS FOR THE GENERAL } \\
\text { MANAGEMENT OF ABI } \\
\text { PATIENTS }\end{array}$ & 8. & $\begin{array}{l}\text { We recommend the use of crystalloids as preferred } \\
\text { maintenance fluids in ABI patients (Strong recommendation). } \\
\text { We recommend against the use of colloids, hypotonic } \\
\text { solutions, glucose-containing hypotonic solutions, or albumin } \\
\text { as maintenance fluids in ABI patients (Strong } \\
\text { recommendation). } \\
\text { We recommend against the use of high-dose albumin } \\
\text { solutions in AIS patients (Strong recommendation). } \\
\text { We suggest using crystalloids as first-line resuscitation fluids } \\
\text { in ABI patients with low blood pressure (Weak } \\
\text { recommendation). } \\
\text { We suggest against the use of synthetic colloids as } \\
\text { resuscitation fluids in ABI patients with low blood pressure } \\
\text { (Weak recommendation). } \\
\text { We recommend against the use of hypotonic solutions and } \\
\text { glucose-containing hypotonic solutions as resuscitation fluids } \\
\text { in ABI patients with low blood pressure (Strong } \\
\text { recommendation). } \\
\text { We suggest against the use of } 4 \% \text { albumin solution as } \\
\text { resuscitation fluid in ABI patients with low blood pressure } \\
\text { (Weak recommendation). } \\
\text { We suggest against the use of } 20 \% \text { albumin as resuscitation } \\
\text { fluid in ABI patients with low blood pressure (Weak } \\
\text { recommendation). } \\
\text { We suggest against the use of hypertonic saline solutions as } \\
\text { resuscitation fluids in ABI patients with low blood pressure } \\
\text { (Weak recommendation). } \\
\text { We suggest that clinicians consider targeting normovolemia } \\
\text { during rement in ABI patients (Weak }\end{array}$ \\
\hline
\end{tabular}




\begin{tabular}{|c|c|c|}
\hline & $\begin{array}{l} \\
12 . \\
13 . \\
14 . \\
19 . \\
16 . \\
16 . \\
\\
\\
16 .\end{array}$ & 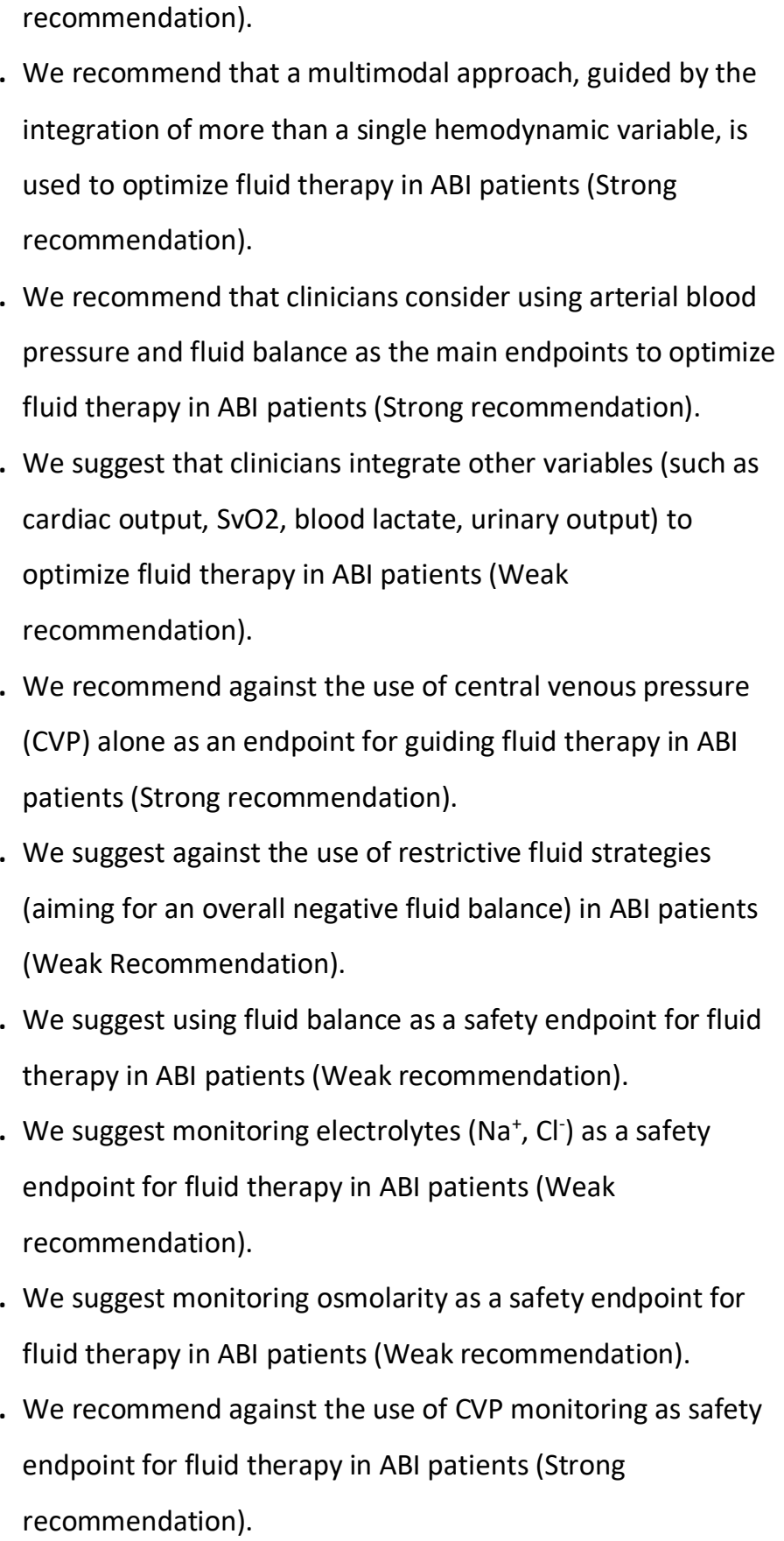 \\
\hline $\begin{array}{l}\text { HYPEROSMOLAR FLUIDS FOR } \\
\text { THE MANAGEMENT OF } \\
\text { ELEVATED ICP }\end{array}$ & 2. & $\begin{array}{l}\text { We suggest that either mannitol or hypertonic saline } \\
\text { solutions be used for reducing increased ICP (Weak } \\
\text { recommendation). } \\
\text { We refrain from giving any recommendations on the use of } \\
\text { hypertonic lactate solutions as a first-line osmotic solutions } \\
\text { for reducing increased ICP (No recommendation) } \\
\text { We suggest that clinicians consider using a pre-defined } \\
\text { trigger for starting osmotherapy to treat elevated ICP (Weak } \\
\text { recommendation) } \\
\text { We recommend that clinicians use a combination of clinical }\end{array}$ \\
\hline
\end{tabular}




\begin{tabular}{|c|c|c|}
\hline & $\begin{array}{l}5 . \\
6 . \\
6 . \\
8 . \\
11 . \\
9 . \\
9 .\end{array}$ & $\begin{array}{l}\text { and neuromonitoring variables for starting osmotherapy to } \\
\text { treat elevated ICP (Strong recommendation) } \\
\text { We recommend a combination of neurological worsening } \\
\text { (defined as a decrease of } 2 \text { points of the GCS motor score, or } \\
\text { loss of pupillary reactivity or asymmetry, or deterioration of } \\
\text { head CT findings) and ICP > } 25 \text { mmHg as a trigger for starting } \\
\text { osmotherapy to treat elevated ICP (Strong recommendation). } \\
\text { We suggest using an ICP threshold > } 25 \text { mmHg independent } \\
\text { of other variables as a trigger for starting osmotherapy to } \\
\text { reduce ICP (Weak recommendation). } \\
\text { We are uncertain whether an ICP threshold } 20-22 \text { mmHg } \\
\text { independent of other variables should be used as a trigger for } \\
\text { starting osmotherapy to reduce ICP (No recommendation). } \\
\text { We recommend against the use of an ICP threshold of } 15 \\
\text { mmHg independent of other variables as a trigger for starting } \\
\text { variables to limit the side effects of osmotherapy (Weak } \\
\text { osmotherapy to reduce ICP (Strong recommendation). } \\
\text { We suggest monitoring serum osmolarity and electrolytes to } \\
\text { limit the side effects of osmotherapy (Weak } \\
\text { recommendation). } \\
\text { We suggest monitoring ICP response to hyperosmolar fluids } \\
\text { to the side effects of osmotherapy (Weak } \\
\text { recommendation). }\end{array}$ \\
\hline $\begin{array}{l}\text { FLUIDS FOR THE MANAGEMENT } \\
\text { OF CEREBRAL ISCHEMIA }\end{array}$ & $\begin{array}{l}1 . \\
2 .\end{array}$ & $\begin{array}{l}\text { We recommend assessing the efficacy of fluid infusion in SAH } \\
\text { patients with } \mathrm{DCl} \text { using a multimodal approach that includes } \\
\text { arterial blood pressure and reversal of neurological deficit as } \\
\text { the main endpoints (Strong recommendation). } \\
\text { We suggest considering reduction of TCD flow velocities, } \\
\text { improvements of cerebral perfusion and reduction of mean } \\
\text { transit time on CT perfusion as secondary endpoints in } \\
\text { assessing the efficacy of fluids for reversal of DCI in SAH } \\
\text { patients (Weak recommendation). }\end{array}$ \\
\hline
\end{tabular}


Table 2. Summary of randomized controlled trials on fluid therapy in neurointensive care patients.

Reference

Population

Patient nr

Intervention

Control

Outcomes

Fluids for the general management (resuscitation and maintenance)

\begin{tabular}{|c|c|c|c|c|c|}
\hline Ginsberg, 2013 & AIS & $\mathrm{N}=841$ & $25 \%$ albumin & N-Saline & Comparable 3-months mRS score \\
\hline Myburgh, 2007 & TBI & $\mathrm{N}=420$ & $4 \%$ albumin & N-Saline & $\begin{array}{l}4 \% \text { albumin group had higher mortality (33.2 } \\
\text { vs. } 20.4 \% \text { in N-Saline group) }\end{array}$ \\
\hline Lehmann, 2013 & SAH & $\mathrm{N}=36$ & Balanced crystalloids/colloids & N-Saline/HES & $\begin{array}{l}\text { Balanced solutions Reduced the rate of } \\
\text { hyperchloremia }\end{array}$ \\
\hline Roquilly, 2013 & TBI & $\mathrm{N}=41$ & Balanced crystalloids/HES & N-Saline/HES & $\begin{array}{l}\text { Balanced solutions reduced the rate of } \\
\text { hyperchloremia }\end{array}$ \\
\hline Shackford, 1998 & TBI & $\mathrm{N}=34$ & $1.6 \%$ HTS & R-Lactate & Comparable GOS at hospital discharge \\
\hline Cooper, 2004 & TBI & $\mathrm{N}=226$ & $7.5 \% \mathrm{HTS}$ & R-Lactate & Comparable 6-months mortality and GOS-E \\
\hline Baker, 2009 & TBI & $\mathrm{N}=64$ & $7.5 \% \mathrm{HTS} / 6 \%$ dextran & N-Saline & Comparable 1-month mortality and GOS \\
\hline
\end{tabular}




\begin{tabular}{|c|c|c|c|c|c|}
\hline \multicolumn{6}{|c|}{ Hyperosmolar fluids for the management of elevated ICP } \\
\hline Ichaï, 2013 & TBI & $\mathrm{N}=60$ & 1/2-molar H-Lactate & N-Saline & $\begin{array}{l}\text { H-Lactate vs. N-Saline had greater efficacy } \\
\text { in preventing ICP elevations and improved } \\
6 \text {-months GOS ( } 60 \text { vs. } 50 \% \text { ) }\end{array}$ \\
\hline Battison, 2005 & $\mathrm{TBI}+\mathrm{SAH}$ & $\mathrm{N}=18$ & $7.5 \% \mathrm{HTS} / 6 \%$ dextran & $20 \%$ MAN & $\begin{array}{l}\text { HTS vs. MAN yielded a greater ICP } \\
\text { reduction }\end{array}$ \\
\hline Francony, 2008 & $\mathrm{TBI}$ & $\mathrm{N}=20$ & $7.5 \% \mathrm{HTS}$ & $20 \%$ MAN & Comparable effectiveness in reducing ICP \\
\hline Cottenceau, 2011 & TBI & $\mathrm{N}=47$ & $7.5 \%$ HTS & $20 \%$ MAN & $\begin{array}{l}\text { Comparable effectiveness in reducing ICP } \\
\text { and mortality }\end{array}$ \\
\hline Ichai, 2009 & TBI & $\mathrm{N}=34$ & 1/2-molar H-Lactate & $20 \%$ MAN & $\begin{array}{l}\text { H-Lactate vs. MAN was more effective in } \\
\text { reducing elevated ICP improved 1-year } \\
\text { GOS ( } 69 \text { vs. } 35 \%)\end{array}$ \\
\hline Vialet, 2003 & TBI & $\mathrm{N}=20$ & $7.5 \%$ HTS & $20 \%$ MAN & $\begin{array}{l}\text { HTS vs. MAN was more effective in } \\
\text { reducing elevated ICP }\end{array}$ \\
\hline Harutjunyan, 2004 & $\mathrm{TBI}+\mathrm{SAH}$ & $\mathrm{N}=32$ & $7.2 \%$ HTS/HES 200/0.5 & $15 \%$ MAN & Comparable effectiveness in reducing ICP \\
\hline Jagannatha, 2016 & TBI & $\mathrm{N}=38$ & $3 \%$ HTS & $20 \%$ MAN & Comparable effectiveness in reducing ICP \\
\hline
\end{tabular}




\begin{tabular}{|c|c|c|c|c|c|}
\hline Sakellaridis, 2011 & TBI & $\mathrm{N}=29$ & $15 \% \mathrm{HTS}$ & $20 \%$ MAN & Comparable effectiveness in reducing ICP \\
\hline Schwarz, 1998 & AIS & $\mathrm{N}=9$ & $7.5 \% \mathrm{HTS} / 6 \%$ dextran & $20 \%$ MAN & Comparable effectiveness in reducing ICP \\
\hline Misra, 2007 & $\mathrm{ICH}$ & $\mathrm{N}=24$ & $20 \%$ MAN & N-Saline & $\begin{array}{l}\text { Comparable effectiveness in reducing MRI- } \\
\text { measured brain shift }\end{array}$ \\
\hline Diringer, 2011 & AIS & $\mathrm{N}=9$ & $23.4 \%$ HTS & $20 \%$ MAN & Comparable effectiveness in increasing CBF \\
\hline \multicolumn{6}{|c|}{ Fluids for the management of cerebral ischemia } \\
\hline Egge, 2001 & SAH & $\mathrm{N}=32$ & $\begin{array}{l}\text { Triple } \mathrm{H} \text { therapy } \\
\text { (4L crystalloids/colloids) }\end{array}$ & $\begin{array}{l}\text { Normovolemia } \\
\text { (2L crystalloids) }\end{array}$ & $\begin{array}{l}\text { Comparable regional } \mathrm{CBF} \text {, and rate of } \\
\text { vasospasm and 1-year GOS }\end{array}$ \\
\hline Lennihan, 2000 & SAH & $\mathrm{N}=82$ & 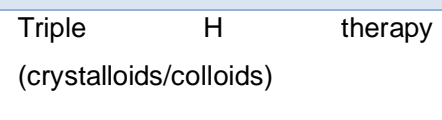 & $\begin{array}{l}\text { Normovolemia } \\
\text { (crystalloids/colloids) }\end{array}$ & $\begin{array}{l}\text { Comparable regional and global } \mathrm{CBF} \text {, and } \\
\text { rate of vasospasm and cerebral infarcts }\end{array}$ \\
\hline $\begin{array}{l}\text { Italian } \quad \text { Acute } \\
\text { Stroke Study } \\
\text { Group, } 1988\end{array}$ & AIS & $\mathrm{N}=1267$ & $\begin{array}{l}\text { Haemodilution } \\
\text { (venisection/dextran } \\
\text { replacement) }\end{array}$ & N-Saline & $\begin{array}{l}\text { Comparable proportion of dead and severely } \\
\text { disabled patients at } 6 \text { months }\end{array}$ \\
\hline
\end{tabular}




\begin{tabular}{|c|c|c|c|c|c|}
\hline Mutoh, 2014 & SAH & $\mathrm{N}=160$ & $\begin{array}{l}\text { Fluid therapy targeted to } \\
\text { transpulmonary thermodilution }\end{array}$ & Standard management & $\begin{array}{l}\text { Comparable rate of delayed cerebral } \\
\text { ischemia and } 3 \text {-months } \mathrm{mRS} \text { scores } 0-3\end{array}$ \\
\hline
\end{tabular}

Abbreviations: AIS, acute ischemic stroke; CBF, cerebral blood flow; GOS, Glasgow Outcome Score; HES, hydroxyl-ethyl starch; H-lactate, hypertonic sodium lactate, HTS, hypertonic saline; ICH, intracerebral hemorrhage; ICP, intracranial pressure; MAN, mannitol; mRS, modified Rankin Scale; N-Saline, normal saline; SAH, subarachnoid hemorrhage; TBI, traumatic brain injury. 
Figure 1. Meta-analysis examining the efficacy of mannitol in reducing ICP.

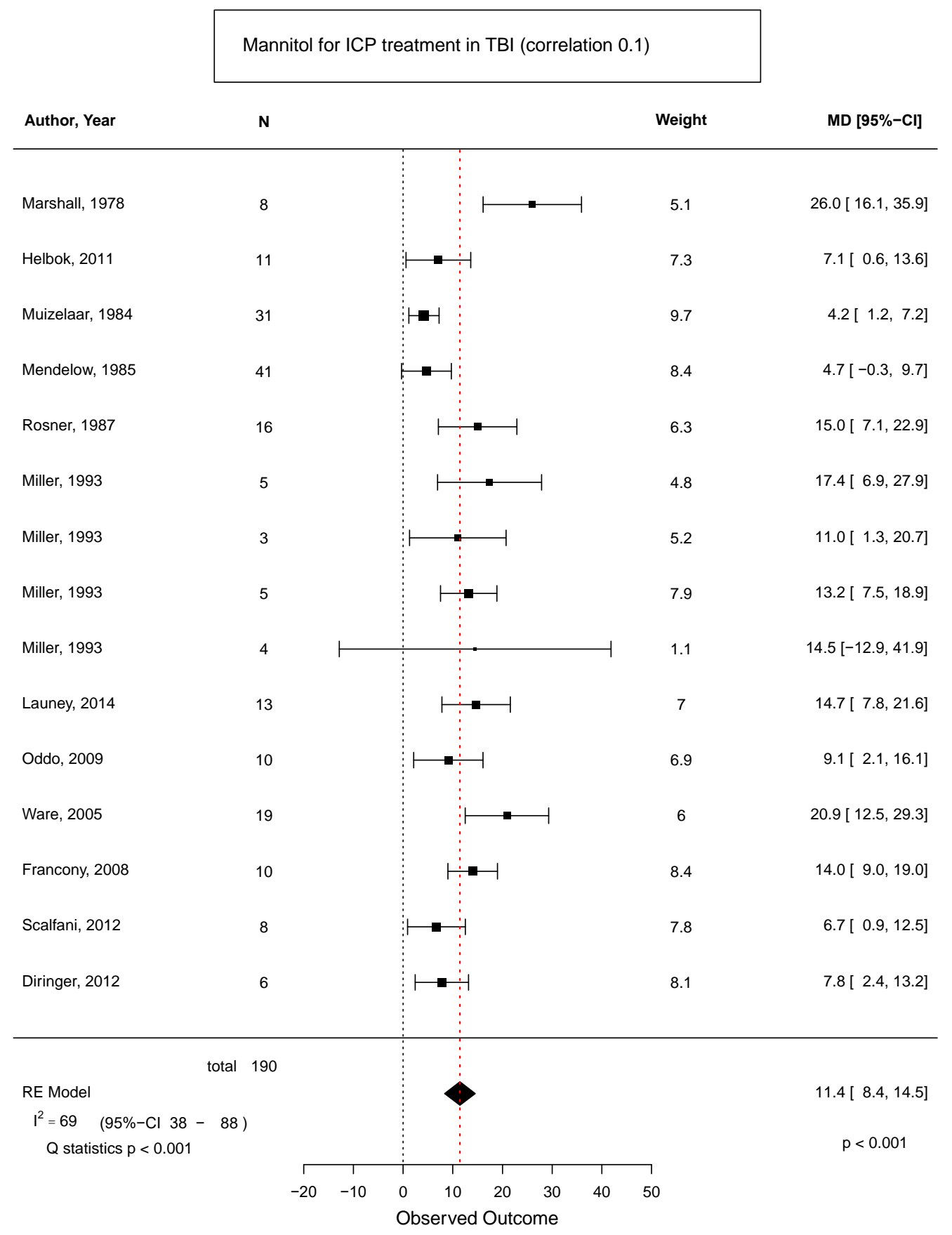


Figure 2. Meta-regression showing the magnitude of mannitol effect on ICP reduction, according to initial pre-treatment ICP.

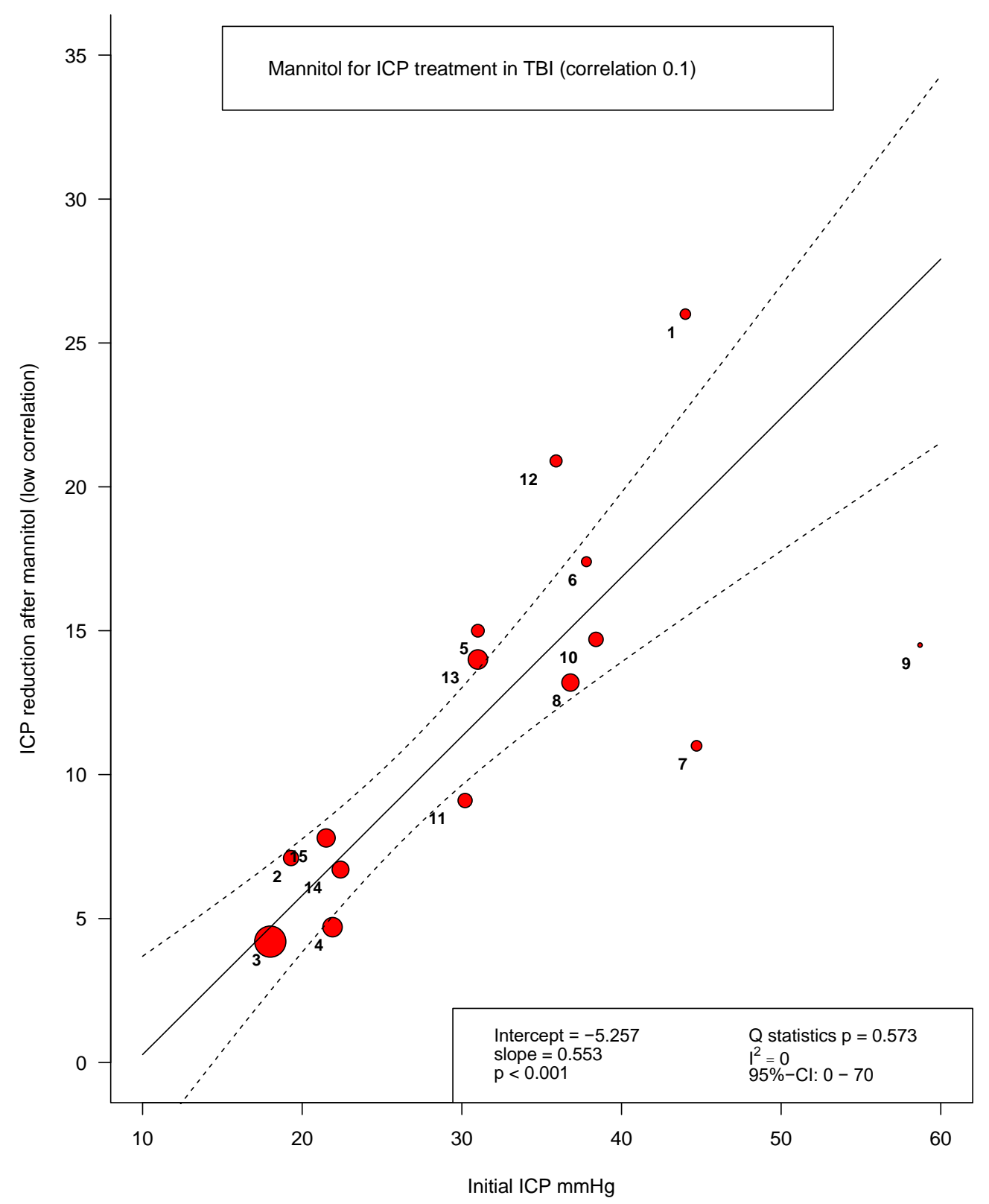


Figure 3. Meta-analysis examining the efficacy of hypertonic saline in reducing ICP.

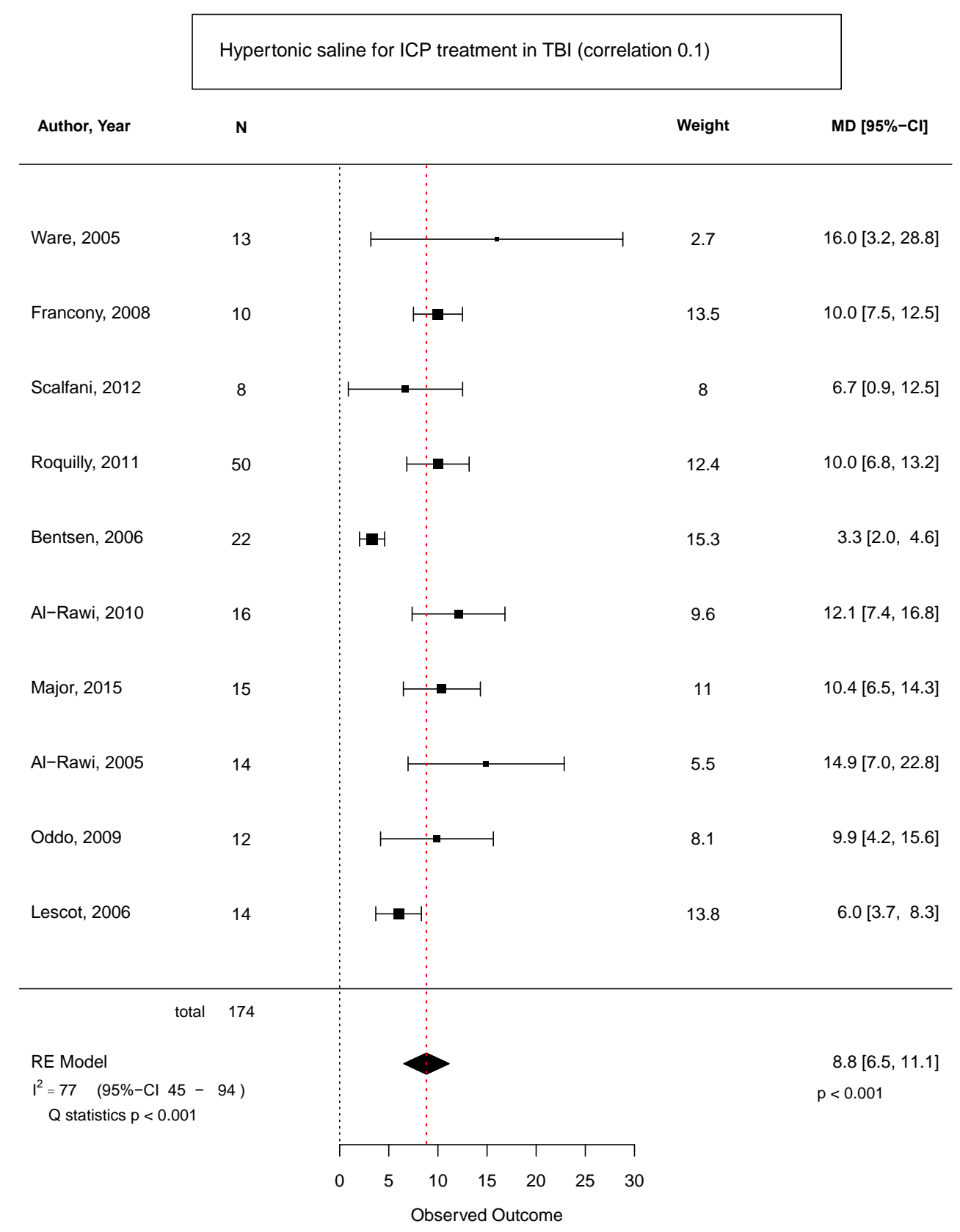


Figure 4. Meta-regression showing the magnitude of hypertonic saline effect on ICP reduction, according to initial pre-treatment ICP.

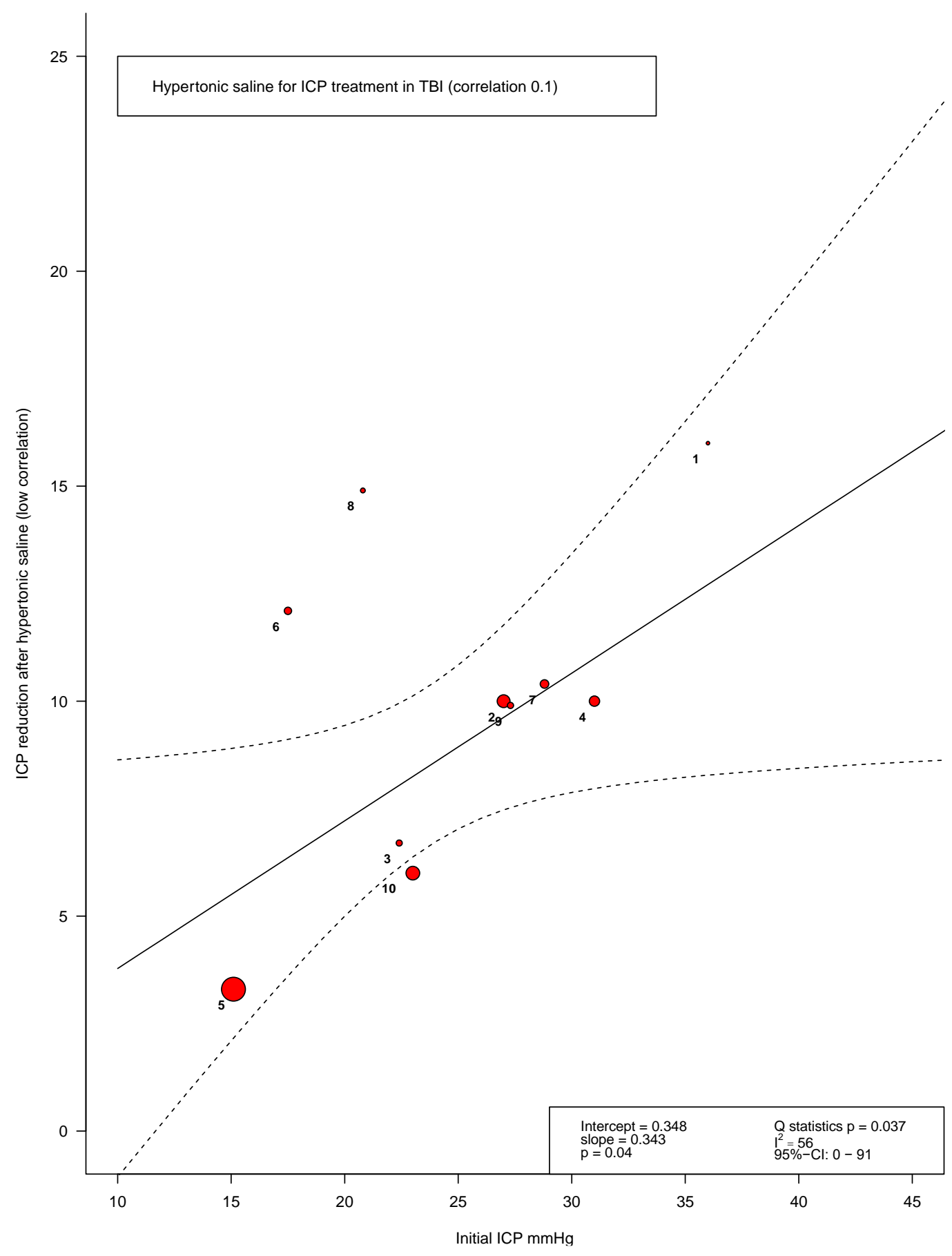

